\title{
DIVERSAS MANIFESTACIONES DE LA VIOLENCIA FAMILIAR.
}

\author{
MARÍA TERESA BAZO
}

Catedrática de Sociología. Universidad del País Vasco.

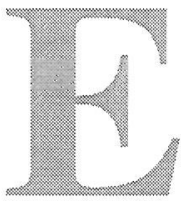

1 maltrato familiar sigue siendo un tema tabú entre nosotros. En España sólo hace dos años que el denominado maltrato doméstico cobró naturaleza de problema social. Muchas mujeres eran víctimas de malos tratos y morían asesinadas por sus compañeros oficiales o sentimentales, actuales o ex. Pero sólo cuando los medios de comunicación se hicieron eco de la horrenda muerte de una mujer quemada viva en su propia casa, empezó a crearse una conciencia social y política del problema. Sobre el maltrato infantil hace ya un tiempo que existe una sensibilidad que se traduce en normativas para que en los centros sanitarios se actúe consecuentemente. Pero únicamente entre los profesionales se habla de los malos tratos a las personas ancianas, aunque los medios de comunicación comienzan también a hacerse eco solicitando información a los expertos. Es debido, sobre todo, a la celebración a principios de abril de la Asamblea Mundial sobre Envejecimiento, organizada por Naciones Unidas, donde se presenta el informe mundial sobre los malos tratos a las personas ancianas.

Sin embargo, el problema de la violencia familiar se aborda en otras sociedades desde hace varias décadas. La consideración del abuso y maltrato de las personas ancianas por parte de sus familiares como un problema social es el último descubrimiento de lo que puede definirse como violencia familiar, y es en los Estados Unidos donde surge por primera vez una preocupación social y política sobre esos problemas. El tema de la violencia cometida en el hogar aparece históricamente en primer lugar bajo la forma del maltrato infantil. Es en los años sesenta cuando comienza a investigarse y publicar sobre dicho problema. La violencia entre cónyuges se hace visible socialmente durante los años setenta, y en los años ochenta se afianza el término "violencia doméstica", que es más utilizado por los movimientos feministas, y con el que se intenta transmitir la idea de que se produce una violencia dentro del hogar, que es perpetrada por los varones contra las mujeres y los niños. El maltrato a las personas de edad fue detectado desde mediados de los setenta, pero no es hasta los ochenta, en los Estados Unidos, cuan- 
do se institucionaliza el término de elder abuse. Es el último descubrimiento de la violencia familiar, aunque en muchos países resulta ser un problema socialmente oculto.

Comenzó a surgir una preocupación social, y política, por el maltrato y actos violentos de cualquier tipo perpetrados en la intimidad del hogar y de la familia. Así, los temas de preocupación surgen y se diría que, al existir esa conciencia social, se amplían, extendiéndose a otras formas de abuso. Surgen preocupaciones por formas específicas de abuso y maltrato, como el abuso sexual de los niños/as, pero no es hasta finales de los años ochenta cuando ese problema específico comienza a considerarse un área de interés y preocupación social al definirse como un problema social (Bennett, Kingston y Penhale 1997: 6).

La violencia familiar se produce debido a las diferencias de poder entre los distintos miembros de la familia. Giddens considera que una explicación de la existencia de la violencia familiar es la combinación existente en la vida familiar de intensidad emocional e intimidad personal. Su existencia es posible por la condescendencia social con la que se ha percibido tradicionalmente. Por otro lado, dentro de la familia se tolera un cierto margen de violencia, lo que no se admite en extraños o en otros entornos sociales. Hasta recientemente la violencia entre cónyuges ha tenido una cierta aceptación social, considerándose que era legítimo en ciertos casos que uno pudiera golpear al otro.

Algunos especialistas consideran que la familia es el grupo social más violento, si exceptuamos, en tiempos de guerra, la policía y el ejército. Es debido a que existe una probabilidad mayor de ser herido, asesinado, o atacado físicamente en la propia casa por alguien con quien se está relacionado, que en cualquier otro contexto social. Hasta recientemente, en España y en otros países, la ley contemplaba la violencia doméstica como un asunto privado. Sin embargo, las causas de la violencia familiar son de carácter estructural (Gelles y Straus, 1988). Desde el feminismo también se pone énfasis en las causas estructurales, por lo que, desde algunas perspectivas, no se está muy de acuerdo con el adjetivo doméstico cuando se habla de la violencia contra las mujeres (Marcus, 1994). Se argumenta que utilizar el término "doméstico" como opuesto al de violencia ejercida por extraños puede minimizar el concepto de violencia, al reducirlo a la esfera privada. Señala Isabel Marcus que "la atribución del término 'relaciones domésticas' a un tema tiende a sacarlo del concepto amplio de derechos civiles" (pág. 27). Eso tiene consecuencias prácticas en cuanto a la conducta de la policía, abogados y jueces, que pueden percibir el incidente como "peleas entre amantes". Entiende la autora (pág. 26) que, a pesar de la designación de "doméstico" como privado, la familia y el Estado son instituciones relacionadas, y lo explica señalando que la familia sociali- 
za a sus miembros para que acepten un modelo de relaciones de género jerárquicas, que perpetúan el dominio del varón sobre la sexualidad, movilidad y trabajo de la mujer, dentro y fuera de casa, mientras el Estado provee las bases legales para que la familia y otras instituciones perpetúen esas relaciones.

En las diversas formas de violencia familiar más comúnmente analizadas, la doméstica, el maltrato infantil y el maltrato a las personas ancianas, existen diferencias y similitudes. En el análisis de la violencia perpetrada contra las personas ancianas se la ha comparado con la ejercida contra los niños/as y, algo menos, con la ejercida contra las mujeres en el hogar. El maltrato infantil y el de las personas ancianas tiene ciertos parecidos, pues, en ambos casos, puede darse la dependencia de la víctima en la persona cuidadora. También pueden darse presiones y estrés. Por otro lado (Penhale y Kingston 1995), también se ha observado, en ambos casos, entre otras características, que, en ocasiones, las familias se encuentran aisladas socialmente y con pocos recursos económicos y sociales; los roles sociales aparecen distorsionados. Otros aspectos parecen también corresponderse entre ambos tipos de violencia, como la evidencia creciente de la transmisión generacional de la violencia, el uso cada vez más fuerte de la violencia como recurso para controlar la conducta tanto de los niños como de los ancianos, que las víctimas son sobre todo mujeres (niñas y ancianas) y, por último, que ambos tipos de conductas violentas se ejercen en una sociedad que se resiste a admitir la existencia de la violencia familiar.

Por otro lado, existen diferencias que se derivan de las situaciones distintas en que se desenvuelven niños y ancianos, ya que la violencia tiene lugar en distintos niveles: sociales e individuales. Ocurre que, mientras culturalmente puede ser admitido el correctivo físico para los niños, no es admitido de ninguna manera para las personas ancianas. Además, los niños suelen ser considerados seres débiles, mientras que las personas mayores pueden ser vistas incluso como "cargantes", por lo que el maltrato infantil resulta siempre más escandaloso. Dentro de la esfera normativa, se tienen nociones sociales claras de lo que es ser "buenos padres" (Penhale y Kingston 1995: 250), pero no queda tan claro qué es o cómo se debe cuidar bien a un anciano/a. De cara a la intervención social, por otra parte, a las personas ancianas se las considera adultas, que pueden aceptar o rechazar un servicio social o de salud, mientras que se actúa de otra manera con los niños/as.

En el micronivel, también se observan diferencias. Los niños víctimas de maltrato no suelen ser discapacitados en su mayoría (aunque ésos sean los que tienen un riesgo mayor), mientras que son más probables víctimas de abuso las personas ancianas discapacitadas o con dificultades emocionales. Por otro lado, el maltrato a las personas an- 
cianas puede ser más difícil de detectar. También puede ocurrir que las familias perciban el cuidado de los niños, y el estrés que conlleva, como algo que terminará un día, al contrario que la dependencia de las personas ancianas. Por último, y dado que en muchos casos la persona cuidadora de una persona anciana puede ser también anciana, en ocasiones el maltratador es también víctima, por la situación que se desarrolla. Es algo que no ocurre en el maltrato infantil.

La violencia contra las personas ancianas no se ha comparado tanto con la violencia contra las mujeres, aunque ésta última se encuentre muy extendida y además se da el caso de que muchas veces continúa a lo largo de la vida hasta la vejez. Otras veces, cambios bruscos en la salud u otras condiciones pueden volver una relación otrora problemática en abusiva. Los cambios en las expectativas, la disminución de la capacidad funcional, el desconocimiento de los efectos de la enfermedad en la conducta, todo ello puede llevar a algún tipo de maltrato. Puede concluirse (Penhale y Kingston 1995) que, aun cuando la relación que incluye maltrato a las personas ancianas no sea entre cónyuges o parejas, el conjunto de la situación en que ocurren esos comportamientos tiene más que ver con la violencia doméstica que con el maltrato infantil. Se trata de personas adultas unidas por relaciones familiares y vínculos emocionales, e incluso de sangre. Se comparte la vivienda más por elección (lo que no ocurre con los niños) y las personas ancianas, por lo general (aunque no siempre), tienen más independencia social, económica y psicológica que los/as niños/as.

Por otro lado, aunque en muchas ocasiones el maltrato a los ancianos es un maltrato entre cónyuges, las respuestas a ambos problemas han funcionado en contextos intelectuales y organizacionales diferentes, debido a que la lucha contra la violencia doméstica ha sido abanderada por los movimientos feministas que la contemplaban ejercida por los maridos/compañeros contra las mujeres y los niños. La preocupación por la violencia contra las personas ancianas, sin embargo, surge entre los profesionales, trabajadores sociales y enfermeras, que descubren los malos tratos.

Al mismo tiempo (Biggs, Phillipson y Kingston 1995), se observan bases comunes para ambos temas, entre las que puede citarse el paralelismo entre el miedo de un varón a perder su dominio, que intenta asegurar las diferencias por género, y ejerce la violencia, y el miedo que podrían padecer los jóvenes a caer en la dependencia y a su propio envejecimiento, que, como se ha observado, es fuente de conflicto en las personas jóvenes, que puede exteriorizarse cuando se encuentran en relación con las personas ancianas. Otro aspecto sería que la violencia doméstica puede verse como un reflejo y última manifestación de las actitudes de la sociedad en general hacia las mujeres, y parale- 
lamente la ejercida contra las personas ancianas como un reflejo del edadismo existente.

Además, se entiende también que, como el estudio y las respuestas a la violencia doméstica han dependido en gran medida de los esfuerzos de los movimientos feministas, el foco de interés ha sido, así, la violencia específica ejercida contra las mujeres, por lo que otros tipos de violencia pueden quedar excluidos. Así, pues, el modelo de violencia doméstica puede ser una contribución a la explicación del maltrato a las personas ancianas. Sin embargo, su alcance es limitado en cuanto al tipo de abuso y negligencia, el enfoque en las víctimas femeninas y en la confianza en el recurso a tomar acciones legales. Todo ello puede restringir su aplicación en el análisis del maltrato a las personas de edad. También puede resultar limitado el modelo a la hora de ejercer la intervención, por las características distintas que configuran los grupos de mujeres adultas y las personas ancianas y por la relación que se ha establecido a lo largo de los años entre las personas ancianas maltratadas y sus maltratadores.

Todo ello supone que el abordaje de los distintos tipos de violencia familiar, debido a sus características específicas, así como su análisis, y su investigación, requieren tratamientos particulares.

Por último, hay que tener en cuenta que la violencia familiar es un tema de los que se consideran "sensibles", dado que afecta a la intimidad de las personas y al mundo íntimo de las relaciones familiares. El abuso y el maltrato sufrido por una persona a manos de otra es un tema de investigación con fuerte carga emocional y de valores, lo que dificulta también la intervención. Se entiende que, cuando ha sucedido un hecho así, el efecto sobre la víctima y quienes intentan solucionarlo puede ser traumático, debido a los tabúes y sanciones sociales que existen sobre el hecho de que una persona haya sufrido maltrato por parte de sus familiares. Eso dificulta que ni la propia víctima ni sus familiares confiesen el hecho, así como que conduce a situaciones de estrés entre los trabajadores sociales y profesionales, a los que se les presentan problemas éticos ante la posibilidad de actuar para acabar con esa situación (Bennett y Kingston 1993: 135-137).

La violencia familiar, su conceptualización, teorización, su abordaje en la investigación y las formas de intervención y prevención, todo ello es fuente de debate y controversia. Además, sólo recientemente se ha considerado que tales formas de violencia no son un mero asunto privado, ni algo incidental que afecta a algunas personas.

Particularizando sobre los malos tratos a las personas ancianas, que es lo que yo especialmente he investigado, señalaré que su existencia e invisibilidad social y política tiene que ver con su estatus social y prestigio más bajo que el de otros grupos de edad, que conlleva prejuicios. 
El edadismo (o prejuicio contra la edad) junto con el sexismo existente contribuyen a esa invisibilidad. En mi investigación sobre el maltrato a las personas ancianas (Bazo, 2001), al analizar por género el porcentaje de personas que sufren algún tipo de abuso, se detecta que proporcionalmente las mujeres sufren algo menos negligencia física y emocional que los varones, pero más maltrato físico y psíquico, así como más abuso económico. Además, sufren más variedad de tipos de malos tratos y mayor número, por lo que las mujeres ancianas frágiles se encuentran en la situación de mayor peligro de sufrirlos. Por otra parte, analizando la relación existente entre padecer dependencia, para unas determinadas actividades de la vida diaria, resulta que, en ciertos casos -como en la negligencia física o psíquica-, se asocia experimentar dependencia para vestirse o controlar los esfínteres con sufrir esos tipos de negligencia. Sin embargo, en ciertos tipos de abuso, como el económico o material, las mujeres son más propensas a sufrirlo, aunque se encuentren menos dependientes que los varones en cuanto a la capacidad para vestirse y moverse. Ser mujer resulta más determinante para sufrir ciertos tipos de maltrato que ser frágil.

En cuanto a las personas ancianas resulta importante, de cara a evitar el maltrato en la mayor medida posible, que las personas sigan manteniendo su estatus social, lo que implica por un lado un cambio de valores en la sociedad, como son: una consideración mayor de la vejez, disminución del valor otorgado a la productividad y erradicación de los prejuicios y estereotipos negativos con los que se percibe la vejez. Por otro lado, el previsible incremento del poder social de las personas de edad y de su influencia política son otras bazas que se pueden llegar a jugar. Tal influencia puede ser pasiva (el simple peso electoral) o activa, por la posibilidad de movilización y de presión. La presión económica también puede ser ejercida. De todos modos, es responsabilidad social contribuir a mantener el respeto y la dignidad de cualquier grupo social al margen de cualesquier otras circunstancias.

En cualquier caso, se hace necesaria una conciencia social del problema, que produzca una conciencia política del mismo, y no sólo entre los científicos y profesionales. Todo ello conllevará la puesta en marcha de políticas de prevención y protección de las personas vulnerables que pueden sufrir malos tratos o desatención. Una de esas políticas, en relación con las personas ancianas -puesto que ya existe para los niños-, tiene que ver con la creación de un protocolo que debería aplicarse en todos los servicios médicos y hospitalarios cada vez que una persona mayor accede a sus servicios. Detectar si sus problemas tienen un origen más o menos voluntario en la conducta de sus cuidadores y coordinar dicha actuación con los servicios sociales es otra asignatura pendiente de nuestras políticas socio-sanitarias. Al mismo 
tiempo, tiene que ponerse en marcha todo un programa de actuación que pasa necesariamente por la coordinación entre los servicios sanitarios y sociales (ya que todavía no existe la coordinación socio-sanitaria como tal).

A continuación, los participantes en esta mesa nos plantearán, desde perspectivas diversas, el maltrato y abuso sexual de los niños y el maltrato a las personas ancianas.

\section{BIBLIOGRAFÍA.}

BAZO, M.T. (2001) :"Negligencia y maltrato a las personas ancianas en España" Revista española de Geriatría y Gerontología, $\mathrm{n}^{\circ} 36$ (1) pp.: 8-14.

BENNETT, G. y KINGSTON, P. (1993): Elder Abuse: Concepts, Theories and Interventions. Londres: Chapman \& Hall.

BENNETT, G., KINGSTON, P. y B. PENHALE (1997): The Dimensions of Elder Abuse: Perspectives for Practitioners. Londres: Macmillan.

BIGGS, S., PHILLIPSON, CH., y KINGSTON, P. (1995): Elder Abuse in Perspective. Buckingham: Open University Press.

GELLES, R.J. y STRAUS, M.A. (1988): Intimate Violence, Nueva York: Simon and Schuster.

MARCUS, I. (1994): "Reframing 'domestic violence': terrorism in the home" en Albertson Fineman, M. y R. Mykitimk, The Public Nature of Private Violence: The Discovery of Domestic Abuse. New York: Routledge: 11-35. PENHALE, B.y KINGSTON, P. (1995): "Similarities, differences and synthesis" en Kingston, P. y B. Penhale, Family Violence and the Caring Proffesions. Basingstoke: Macmillan: 245-261. 